\title{
Kanonessammlungen als Fundorte für päpstliche Schreiben
}

\author{
LOTTE KÉRY
}

„Papsturkunden ohne Ende“ - mit diesem Stoßseufzer begann nicht nur Paul Fridolin Kehr im Jahre 1905 den ersten seiner Berichte mit dem Titel „Nachträge zu den Papsturkunden Italiens", sondern auch Rudolf Hiestand stimmte vor 10 Jahren in seinem Göttinger Vortrag „100 Jahre Papsturkundenwerk“ erneut in dieses Lamento ein $^{1}$, das wohl vor allem auf die Italia pontificia zutrifft, die mit bisher 11024 Regesten den größten Umfang der nationalen Papsturkundenwerke darstellt. Vor diesem Hintergrund dürfte es schwerfallen, den Bearbeitern noch weitere Fundorte für ihre Sammel- und Editionstätigkeit päpstlicher Schreiben zu empfehlen, die außerdem noch erhebliche Schwierigkeiten bei der Erschließung bieten - wie die kanonistischen Sammlungen.

Von Anfang an war man sich dieser Schwierigkeiten bewußt. Kehr - nach eigener Einschätzung „,reinster Diplomatiker Sickelscher Observanz “2 - wollte in seinem ursprünglichen Plan noch das ganze in Registern, Brief- und Kanonsessammlungen enthaltene kanonistische Material bewußt ausschließen ${ }^{3}$. Ein halbes Jahrhundert später dehnte dagegen Walther Holtzmann, der um mit den Worten Rudolf Hiestands zu sprechen, „weniger Diplomatiker als Historiker mit ausgeprägten kirchenrechtlichen Interessen" war $^{4}$, schon einmal mit Nachdruck das Aufgabenfeld auf die Kanonistik aus, als er damit begann, die Dekretalensammlungen zwischen Gratian und dem «Liber Extra» Gregors IX. für die Italia pontificia auszuwerten und als erstes eine Liste von Dekretalen

1 Rudolf Hiestand: 100 Jahre Papsturkundenwerk, in: Hundert Jahre Papsturkundenforschung. Bilanz - Methoden - Perspektiven, hg. v. Rudolf Hiestand, Göttingen 2003 (AAG phil.-hist. Kl., 3. Folge 261), S. 11-46, hier S. 44.

2 Vgl. Walther Holtzmann: Kanonistische Ergänzungen zur Italia Pontificia, in: QFIAB 37 (1957) S. 55-102; 38 (1958) S. 67-175 (Separatdruck Tübingen 1959) hier QFIAB 37, S. 55.

3 Hiestand (wie Anm. 1) S. 32; vgl. dazu auch Paul F. Kehr: Ueber den Plan einer kritischen Ausgabe der Papsturkunden bis Innocenz III., in: NGG, Geschäftliche Mitteilungen (1896) S. 72-86, hier S. 76-77 (ND in: Paul Fridolin KeHr: Ausgewählte Schriften, hg.v. Rudolf Hiestand, Bd. 1, Göttingen 2005 [AGG phil.-hist. Kl., 3. Folge 250], S. 3-17). Kehr hatte zwar einzelne dieser Dekretalensammlungen, die schon früher bekannt waren, in den Bänden der Italia pontificia verzeichnet, aber „eine Vollständigkeit der handschriftlichen Quellen für die kanonistisch überlieferten Papstbriefe hat er nicht angestrebt, da von Anfang an ihre Herausgabe dem ursprünglichen Plane ferne lag", Holtzmann: Ergänzungen (wie Anm. 2) S. 56.

4 Hiestand (wie Anm. 1) S. $32 \mathrm{f}$. 
herausgab, die in Sammlungen vor der "Compilatio secunda», also vor 1210/ 1212, zu finden sind ${ }^{5}$.

Holtzmann wollte in diesem Zusammenhang unter Dekretalen, wie er ausdrücklich betont, „diejenigen Briefe und Erlasse [verstehen], die wir nur aus der kanonistischen Überlieferung kennen, aus zunächst privaten und anonymen Sammlungen, wie sie nach dem Erscheinen von Gratians Dekret in großer Fülle entstanden und schließlich einmündeten in die offizielle Kodifikation Gregors IX." ${ }^{~}$ Dem berechtigten Einwand Kuttners, daß diese Definition zu eng gefaßt sei $^{7}$, begegnete er mit dem Hinweis, daß die Bezeichnung Dekretalen für seine Arbeit vor allem die unbeholfene Formulierung „kanonistisch überlieferte Papstbriefe" ersetzen sollte, denn es ging ihm ja hier vor allem um eine überlieferungsbedingte Abgrenzung zu den übrigen Papsturkunden und nicht um eine genauere inhaltliche Beschreibung der Dekretalen ${ }^{8}$.

Mit seinen „Kanonistischen Ergänzungen zur Italia Pontificia“, konnte er an konkreten Fällen zeigen, „wieviel dieser Quellengattung auch für die Regestenbände abzugewinnen war" ${ }^{\text {"9. }}$. Im Sinne des von Kehr formulierten Zieles, eine "möglichste Vollständigkeit in der Sammlung des Materials“ anzustreben ${ }^{10}$, hielt Holtzmann die kanonistischen Quellen für unverzichtbar, da sie vollständige Texte oder zumindest Bruchstücke davon liefern konnten, auf die bei der Herstellung, Datierung und Lokalisierung und schließlich auch bei der Interpretation der eigentlichen „Urkunde“ nicht verzichtet werden konnte ${ }^{11}$. Sein Programm lautete, daß das kanonistisch überlieferte Material insgesamt verzeichnet werden müsse, neugefundene Texte wären zu publizieren und auch für die schon registrierten Papsturkunden könnten schließlich aufgrund des beträchtlich vermehrten Überlieferungsmaterials Korrekturen vorgenommen werden ${ }^{12}$. Prinzipiell sind also von den kanonistischen Sammlungen sowohl neue Texte als auch zusätzliche Überlieferungen bereits bekannter Texte, die ergänzende Informationen zum Inhalt und zur historischen Einordnung der Stücke bieten könnten, zu erwarten.

Gleichzeitig plädierte Holtzmann jedoch auch dafür, die vollständige Aufzählung der gesamten handschriftlichen Überlieferung dieser kanonistisch

5 Ebd. S. 32; Walther Holtzmann: Über eine Ausgabe der päpstlichen Dekretalen des 12. Jahrhunderts, in: NGG phil.-hist. Kl. (1945), S. 15-36; Holtzmann: Ergänzungen (wie Anm. 2).

6 Holtzmann: Ergänzungen (wie Anm. 2) S. 56.

7 Stephan Kuttner: Notes on a Projected Corpus of Twelfth-Century Decretal Letters, in: Traditio 6 (1948) S. 345 Anm. 3.

8 Holtzmann: Ergänzungen (wie Anm. 2) S. 56 Anm. 5.

9 Hiestand (wie Anm. 1) S. $32 \mathrm{f}$.

10 Holtzmann: Ergänzungen (wie Anm. 2) S. 56.

11 Holtzmann: Ergänzungen (wie Anm. 2) S. 57.

12 Holtzmann: Ergänzungen (wie Anm. 2) S. 57. 
überlieferten Texte nicht in den Regesten der Italia pontificia, sondern in ergänzenden Werken vorzunehmen, um den Benutzer nicht zu verwirren ${ }^{13}$ und wie man hinzufügen könnte - das Material mit den Hinweisen auf die zum Teil sehr umfangreiche kanonistische Überlieferung nicht unsachgemäß aufzublähen.

Mit seinen „Kanonistischen Ergänzungen“, die das Regestenwerk nicht nur ergänzen, sondern auch entlasten sollten, stellte Holtzmann also auch die Weichen dafür, daß die Erfassung der Dekretalen zu einer eigenen Abteilung unter der Leitung von Stephan Kuttner († 1996) in Berkeley ausgebaut wurde. Leider ist das Werk der «Regesta decretalium», das einen Gesamtüberblick auf der Grundlage des Nachlasses von Walther Holtzmann liefern sollte und eine hervorragende Ergänzung zum Papsturkundenwerk bieten könnte, bisher über Anfänge nicht hinausgekommen ${ }^{14}$. Inzwischen werden jedoch Holtzmanns Karteikarten in digitalisierter Form auf der Internetseite des Stephan-KuttnerInstitutes in München zugänglich gemacht ${ }^{15}$.

Obwohl Holtzmann selbst sich zunächst den nachgratianischen Dekretalensammlungen zugewandt hatte, sprach er auch die Empfehlung aus, daß die Arbeit, die er für die Zeit zwischen Gratian und der "Compilatio secunda» in Angriff genommen habe, in ähnlicher Weise für die vorgratianischen Sammlungen unternommen werden müßte. Er gesteht zwar zu, daß dies eine noch umfangreichere und - wie man hinzufügen muß - wohl auch noch schwierigere Aufgabe wäre, verweist jedoch hinsichtlich ihres großen Nutzens gerade auch für die Historiker auf den Band von Gassó und Batlle über die Briefe Pelagius' I. ${ }^{16}$

$\mathrm{Da}$ also für die nachgratianischen Dekretalensammlungen zumindest zum Teil schon gezeigt wurde, daß ihre Einbeziehung sinnvoll und ertragreich ist, möchte ich mich heute den vorgratianischen Sammlungen zuwenden und versuchen, in groben Zügen die Bedeutung oder besser gesagt die Problematik dieser Sammlungen als Fundorte für päpstliche Schreiben darzustellen und die Besonderheiten dieser Überlieferung in chronologischer Abfolge an einigen Beispielen aufzuzeigen.

13 Holtzmann: Ergänzungen (wie Anm. 2) S. 57.

14 Vgl. dazu auch schon Peter Landau: Die Entstehung der systematischen Dekretalensammlungen und die europäische Kanonistik des 12. Jahrhunderts, in: ZRGKanAbt 65 (1979) S. 120-148, hier S. 121.

15 Internetadresse: www.kuttner-institute.jura.uni-muenchen.de/holtzmann_formular.htm (01.01.2008).

16 Pius M. Gassó/Columba M. Batlle: Pelagii I papae epistulae quae supersunt, Montserrat 1956 (Scripta et documenta 8); vgl. Holtzmann: Ergänzungen (wie Anm. 2) S. 56 Anm. 5. 
Ähnlich wie die Dekretalensammlungen der nachgratianischen Zeit überliefern auch die kanonistischen Sammlungen, die vor dem «Decretum Gratiani» (um 1140) entstanden sind, nicht nur - wie es der Name zunächst vermuten läßt Kanones oder Konzilsbeschlüsse, sondern auch Dekretalen, epistolae oder litterae decretales, das heißt ganz spezielle Papstbriefe, die sich nicht nur durch die besondere Form ihrer Überlieferung, sondern auch inhaltlich von den feierlichen Privilegien und den übrigen päpstlichen litterae unterscheiden. Dekretalen zeichnen sich dadurch aus, daß sie eine päpstliche Entscheidung übermitteln, ihr Ziel ist die Normgebung und die Festsetzung vor allem disziplinarischer Regeln ${ }^{17}$. Technisch gesprochen handelt es sich dabei meist um Responsa oder Reskripte, die nach dem Vorbild der spätantiken Kaiserreskripte autoritative Antworten gaben auf eine Appellation oder eine Bitte um Rechtsauskunft in einem konkreten Fall, die an den Hl. Stuhl gerichtet wurden.

Diese inhaltliche Einschränkung prädestinierte solche päpstlichen Schreiben für eine Aufnahme in kirchenrechtliche Sammlungen. Das heißt jedoch umgekehrt nicht, daß man in kanonistischen Sammlungen nicht auch andere Papstbriefe findet, die sich etwa mit Verwaltungsangelegenheiten beschäftigen oder auch reine Freundschaftsbriefe, wie z. B. der von Hageneder zitierte Brief Papst Innozenz' I. an eine vornehme Dame Juliana (JK 302), in dem der Papst ihren religiösen Eifer lobt und sie ermahnt, diesen auch in Zukunft beizubehalten ${ }^{18}$.

Dies gilt speziell für die vorgratianischen Sammlungen, denn in ihrer Entstehungszeit hat man unter dem Begriff ,Dekretale' noch in einem sehr weiten Sinne „alle Schreiben von Belang, die für kirchenrechtliche Fragen einmal Bedeutung erlangen konnten "19, verstanden. So enthält etwa die gegen Ende des 11. Jahrhunderts entstandene "Collectio Britannica» noch die in die Jahre 558/60 zu datierende Anweisung Pelagius' I. an einen comes Gurdimer, die Wiesen an der Straße nach Porto mähen zu lassen ${ }^{20}$. Auch Detlef Jasper hat vor

17 Charles Duggan: Art. Decretals (epistolae decretales, litterae decretales); Decretals, Collections of', in: NCE 4 (1967) S. 707-711, hier S. 707; vgl. Detlev Jasper: The Beginning of the Decretal Tradition. Papal Letters from the Origin of the Genre through the Pontificate of Stephen V., in: Ders./Horst Funrmann: Papal Letters in the Early Middle Ages, Washington D.C. 2001 (History of Medieval Canon Law), S. 3-133, hier S. 19.

18 Othmar Hageneder: Papstregister und Dekretalenrecht, in: Recht und Schrift im Mittelalter, hg. v. Peter Classen, Sigmaringen 1977 (VuF 23) S. 319-347, hier S. $327-$ 328; Jasper (wie Anm. 17) S. 36 („private letter[s]“).

19 Hageneder (wie Anm. 18) S. 327.

20 JK 1034; Gassó-Batlle (wie Anm. 16) S. 191; vgl. Hageneder (wie Anm. 18) S. 328; Jasper (wie Anm. 17) S. 65 Anm. 276. 
kurzem noch einmal betont, daß eine absolute Trennung zwischen Dekretalen und Papstbriefen letztlich unmöglich ist ${ }^{21}$ - oder wie Stanley Chodorow es formuliert hat: „Decretals are papal letters, but exactly what type of letters is hard to define." ${ }^{22}$ Im neunten Jahrhundert konnte sogar noch jeder Papstbrief als epistola decretalis gekennzeichnet werden ${ }^{23}$.

Auch diese fehlende Trennschärfe zwischen Dekretalen und Papstbriefen unterstreicht die Notwendigkeit, die päpstlichen Schreiben, die man in Kanonessammlungen findet, in das Papsturkundenwerk miteinzubeziehen, denn wir haben es hier mit päpstlichen Schreiben zu tun, die zwar in erster Linie rechtliche Inhalte transportieren, aber zugleich auch dazu beitragen können, die Beziehungen des Papsttums zu den einzelnen Ortskirchen genauer zu beschreiben.

Obwohl häufig der Eindruck erweckt wird, als gebe es Dekretalen erst seit der zweiten Hälfte des 12. Jahrhunderts ${ }^{24}$, stammt die nach heutigem Kenntnisstand älteste echte Dekretale (JK 255) von Papst Siricius $(384-399)^{25}$ und damit vom Ende des 4. Jahrhunderts - und schon im 5. und 6. Jahrhundert wurden solche päpstlichen Schreiben dann auch zu Sammlungen zusammengestellt bzw. in Kanonessammlungen aufgenommen ${ }^{26}$. Es fällt auf, daß diese frühen Dekretalen sich an weiter entfernte Adressaten wenden - die acht Dekretalen, die in den ältesten italienischen und gallischen Sammlungen des 5. und 6. Jh. gefunden werden, gehen nach Nordspanien (Tarragona), Gallien (Rouen, Toulouse, Vienne, Narbonne), nach Makedonien und Dacien sowie nach Salona an der dalmatischen Küste (heute Kroatien) ${ }^{27}$. Adressat in Italien ist lediglich Decentius von Gubbio in dem bekannten Schreiben Innozenz' I. (JK 311), das ebenfalls zu dieser Gruppe gehört. ${ }^{28}$ Andererseits findet sich etwa die Dekretale des Papstes Siricius an die Bischöfe der römischen Kirchenprovinz über die Weihe von Priestern und Bischöfen (JK 263) allein in der «Collectio Hispana ${ }^{29}$.

21 Jasper (wie Anm. 17) S. 20 Anm. 74. Vgl. dort auch S. 12 (,Definition of a Decretal').

22 Stanley Chodorow: Art. Decretals, in: Dictionary of the Middle Ages 4 (1984) S. $122-$ 124, hier S. 122.

23 Jasper (wie Anm. 17) S. 20 Anm. 74.

24 Vgl. dazu Jasper (wie Anm. 17) S. 12.

25 Peter Landau: Rechtsfortbildung im Dekretalenrecht. Typen und Funktionen der Dekretalen des 12. Jahrhunderts, in: ZRGKanAbt 86 (2000) S. 86-131, hier S. 87; JAsper (wie Anm. 17) S. 9-12; dort auch (S. 11, Anm. 31) die Ankündigung einer Neuedition dieser Dekretale durch Klaus Zechiel-Eckes.

26 Jasper (wie Anm. 17) S. 22-34.

27 Ebd. S. 22; vgl. dort auch S. 20 Anm. 77.

28 Ebd. S. $27 \mathrm{f}$.

29 Später wurde sie in die Sammlung der pseudoisidorischen Dekretalen aufgenommen und auch in vorgratianischen Sammlungen - wahrscheinlich wegen ihres Inhalts - häufig zitiert, JASPER (wie Anm. 17) S. 35. 
Dies zeigt ebenso wie die verbreitete Praxis, Dekretalen oder sogar ganze Dekretalenblöcke aus früheren Kanonessammlungen in neue Sammlungen zu übernehmen, daß man die Suche nach Dekretalen mit italienischen Adressaten keinesfalls auf Sammlungen beschränken kann, die in Italien angelegt wurden, ganz abgesehen davon, daß die Bestimmung des Entstehungsortes sich für so manche Sammlung als äußerst schwierig erweist ${ }^{30}$.

Die bekannteste und wohl auch im Hinblick auf ihre Folgewirkung wichtigste Sammlung aus der frühen Zeit ist die Sammlung von 38 Dekretalen, die Dionysius Exiguus um 500 zusätzlich zu seiner eigentlichen Kanonessammlung, d. h. seiner Sammlung von Konzilsbeschlüssen, zusammenstellte ${ }^{31}$. Dies war für die Kanonistik ein wichtiger Meilenstein, denn mit dieser berühmten Sammlung päpstlicher Schreiben wurde zum erstenmal Dekretalenrecht gleichberechtigt neben Konzilsrecht gestellt ${ }^{32}$. Anschließend wurde dann die «Dionysiana» selbst zu einer wichtigen Quelle für Papstbriefe, denn die Version, die auch die Dekretalen enthält, wurde für die wichtigsten vorkarolingischen systematischen Sammlungen einschließlich der "Concordia canonum» des Cresconius und der «Vetus Gallica» benutzt ${ }^{33}$. Alle päpstlichen Dekretalen der «Dionysiana» wurden zudem in die chronologische Version der "Collectio Hispana» übernommen ${ }^{34}$.

Damit zeigt sich eine weitere grundsätzliche Schwierigkeit für die Erschließung des kanonistisch überlieferten Textmaterials, die darin besteht, daß

$30 \mathrm{Zu}$ dieser Problematik und zu der Frage, ob Anhaltspunkte für den Entstehungsort auch von den Adressaten der Dekretalen abgeleitet werden können, vgl. auch Holtzmann: Ergänzungen (wie Anm. 2) S. 69-71. Er betont, daß „italienische“ Dekretalen nicht nur durch italienische Sammlungen überliefert werden, sondern sie kommen auch in „Zweifelsfrei“ englischen und französischen Sammlungen vor, manchmal sogar „in besserer Textform“. Zudem weist er darauf hin, daß die «Collectiones Cheltenhamenensis» und "Cottoniana» sogar ,italienische“ Texte enthalten haben, die sonst in der gesamten Überlieferung fehlen. Dies sei nur durch „intensive Sammeltätigkeit“ zu erklären, „welche zu verschiedenen Zeiten und durch verschiedene Interessenten aus allen Ländern zentrale kirchliche Quellen, also das päpstliche Archiv, ausgebeutet hat" (S. 70).

31 Hubert Wurm: Studien und Texte zur Dekretalensammlung des Dionysius Exiguus, Bonn 1939 (Kanonistische Studien und Texte 16). Dekretalen der Päpste Siricius, Innozenz I., Zosimus, Bonifacius I., Cölestin I., Leo I., Gelasius I. und Anastasius II. wurden im Nachhinein der zweiten Version der «Dionysiana» hinzugefügt. Linda Fowler-Magerl: Clavis Canonum. Selected Canon Law Collections Before 1140. Access with data processing, Hannover 2005 (MGH Hilfsmittel 21), S. 29-32, v.a. S. 31.

32 Landau: Entstehung (wie Anm. 14) S. 120. Übersicht über Handschriften, Editionen und Literatur zur "Dionysiana»: Lotte Kéry: Canonical Collections of the Early Middle Ages (ca. 400-1140): A Bibliographical Guide to the Manuscripts and Literature, Washington D.C. 1999 (History of Medieval Canon Law), S. 11-21.

33 Fowler-Magerl (wie Anm. 31) S. 31.

34 Ebd. S. 31. 
die Papstbriefe in den Kanonessammlungen in vielen Fällen sogar mehrfach indirekt überliefert sind ${ }^{35}$. Als erstes ist deshalb mit Rudolf Hiestand hervorzuheben, daß die kanonistisch überlieferten Papstbriefe für eine Diplomatik der Papsturkunden im engeren Sinne, d.h. bezüglich Form und Kanzlei, in der Regel nichts ergeben ${ }^{36}$. Auf der anderen Seite verdienen es natürlich gerade die päpstlichen Schreiben, die immer wieder in andere Kanonessammlungen übernommen wurden, als Texte, die weithin zirkulierten und von vielen gelesen und benutzt wurden, auch in besonderer Weise in ihren verschiedenen Versionen rekonstruiert zu werden, was sich jedoch aufgrund der reichen handschriftlichen Überlieferung auch als besonders schwierig erweist ${ }^{37}$.

Gleichzeitig stellt sich die Frage, wie es um die Authentizität dieser in Kanonessammlungen tradierten Papstbriefe bestellt ist. Wie schon Hubert Wurm erkannte, stammen die Papstbriefe, die wir in der "Dionysiana» finden und das gilt auch für die meisten anderen frühen kanonistischen Sammlungen -, nicht unmittelbar aus den päpstlichen Archiven ${ }^{38}$. „Es ist also sicher“, schreibt Wurm, „so sehr die Dekretalensammlung des Dionysius Exiguus in der Wertschätzung steigen müßte, wenn die Registerbücher des päpstlichen Archivs als ihre Quelle erwiesen werden könnten, so steht doch fest, daß alle auffindbaren Kennzeichen bezeugen, daß dies nicht der Fall war. ${ }^{\text {“39 }}$

Registerbenutzung der Sammler gilt demnach als ein wichtiges Kriterium für die Authentizität und Verläßlichkeit der Texte, ein Aspekt der natürlich auch für die Gewinnung und Einschätzung von Texten aus den Kanonessammlungen für die Italia pontificia von großer Bedeutung ist. Im Hinblick auf eine Identifizierung „neuer“ Papsturkunden oder auch Ergänzung und Korrektur bekannter Papsturkunden mit Hilfe der kanonistischen Überlieferung ginge es also nicht nur darum festzustellen, in welchen Sammlungen Papstbriefe mit italienischen Adressaten enthalten sind, sondern auch, in welchen Sammlungen diese erstmals tradiert werden, welche Papstbriefe unmittelbar aus den päpstlichen

35 Dazu auch Kuttner: Notes (wie Anm. 7) S. 345.

36 Hiestand (wie Anm. 1) S. 33.

37 Kuttner: Notes (wie Anm. 7) S. 345.

38 Wurm (wie Anm. 31) S. 190 f.; Fowler-Magerl (wie Anm. 31) S. 31.

39 Dies wird unter anderem daraus abgeleitet, daß Unregelmäßigkeiten im Protokoll vorkommen und die Datierung in den Schreiben fehlt, vgl. JAsper (wie Anm. 17) S. 36. Wurm weist zudem darauf hin, daß Dionysius eigens vermerkte, wenn er Texte aufnahm, die unmittelbar aus den römischen Archiven stammten. Vgl. Wurm (wie Anm. 31) S. 230: „Für eine Benützung des römischen Archivs durch Dionysius ist also keinerlei Anhaltspunkt gegeben; wohl aber bezeugt Dionysius selbst indirekt, daß es nicht der Fall war. [...] Dionysius macht eigens darauf aufmerksam, wenn er Material benützt, das direkt aus dem römischen Archiv stammt; also ist das Schweigen darüber bei der Dekretalensammlung beweiskräftig. [...] Vgl. dort auch S. 228: „Dionysius aber hatte persönlich keinen Zugang zu den päpstlichen Regesten [!], und auch seine Sammlung beruht nicht auf Registerauszügen." 
Archiven oder Registern stammen oder möglicherweise auch nachträglich anhand von Archiv- oder Registerversionen korrigiert wurden.

Als eine solche Sammlung, bei der die unmittelbare Verwendung der Papstregister zumindest für die 138 Briefe des Papstes Hormisda aus den Jahren 515 bis 521 feststeht, hat die um 555 entstandene, chronologisch angelegte «Collectio Avellana» zu gelten ${ }^{40}$, die jedoch nur noch in Handschriften des 11. Jahrhunderts überliefert ist. Neben den Briefen des Papstes Hormisda enthält sie auch Schreiben anderer Päpste des 5. und 6. Jahrhunderts, wie des Simplicius (468-483), Gelasius (492-496), Symmachus (514), Johannes' II. (532-535), Agapet (535/536) und Vigilius (537-555) und stellt auch die einzige Überlieferung für fünf Briefe Papst Leos I. (JK 546-550) dar, die auf den 17. Juni und 18. August 460 datiert sind. Ähnlich wie auch spätere Sammlungen dieses Typs, wie z. B. die noch eingehender zu besprechende "Collectio Britannica», scheint die "Avellana» jedoch keinen größeren Einfluß auf andere vorgratianische Sammlungen ausgeübt zu haben ${ }^{41}$.

Offenbar waren sich auch schon die Sammler bewußt, daß die Überlieferung der Papstschreiben in kanonistischen Sammlungen gewisse Probleme im Hinblick auf die Glaubwürdigkeit der Texte aufwerfen konnten und suchten sich deshalb durch eine nachträgliche Überprüfung abzusichern. So übernahm etwa der Kardinalpriester Gregor von San Grisogono für seine Sammlung «Polycarpus» um die Wende vom 11. zum 12. Jahrhundert Briefe Papst Gregors I. aus früheren Sammlungen, griff jedoch anschließend unmittelbar auf dessen Register zurück, um die Inskriptionen zu vervollständigen ${ }^{42}$. Die hier aufscheinende Problematik, daß die Inskriptionen und damit die Nennung der Adressaten in den Dekretalen - gelinde gesagt - nicht immer zuverlässig und vor allem häufig unvollständig sind, stellt für die Erschließung päpstlicher Schreiben aus Kanonessammlungen ein ganz fundamentales Problem dar, wie später noch an einigen Beispielen zu zeigen sein wird.

40 Vgl. Hageneder (wie Anm. 18) S. 321 (dort auch eine Aufzählung der Indizien für Registerbenutzung).

41 Jasper (wie Anm. 17) S. 84; vgl. auch Otto GüNTHer: Epistulae Imperatorum, Pontificum, aliorum inde ab anno 367 ad annum 553 datae Avellana quae dicitur collectio, Wien 1895-1898 (CSEL 35/1-2). Möglicherweise wurde die "Collectio Avellana» von dem Redaktor der italienischen 2-Bücher-Sammlung des Vat. lat. 3832 für einige Gelasianische Exzerpte benutzt, vgl. Jasper (wie Anm. 17) S. 83-85; sie enthält auch den vollständigen Text von JK 664 (Gelasius' Rechtfertigung der Verhängung des Anathems über Acacius), der sonst immer nur ohne Schluß in zahlreichen Sammlungen überliefert ist (ebd. S. 85).

42 Vgl. Fowler-Magerl (wie Anm. 31) S. 231; zur Benutzung von Gregor-Briefen vgl. auch Jasper (wie Anm. 17) S. 79-80; Ute-Renate Blumenthal stellte zudem fest, daß Gregor von San Grisogono auch die offizielle Version der Dekrete des Konzils von Clermont benutzte, d. h. die Form, die im Register oder für das Register verbessert wurde (Fowler-Magerl S. 231). 
Hageneder hat in seinem Beitrag über Papstregister und Dekretalenrecht die Phase bis ca. 1200 jedenfalls als „Zeit einer losen und eher zufälligen Beziehung zwischen Papstdekretalen und Registern" gekennzeichnet ${ }^{43}$. Die Dekretalen der Päpste seien zwar meist auf dem Wege über Auszüge aus ihren Registern bekannt geworden, diese hätten jedoch nicht immer systematisch alle vorhandenen Bücher erfaßt. Auf solche Exzerpte hätten sich dann die Kompilatoren der kanonistischen Sammlungen wohl vorwiegend gestützt, die diese Schreiben jedoch auch längst nicht immer vollständig in ihre Sammlungen übernahmen ${ }^{44}$.

Vollständige Papstbriefe kann man prinzipiell eher in den chronologisch geordneten Sammlungen erwarten, in denen die Texte zum Teil auch im vollen Wortlaut wiedergegeben werden und nicht schon nach inhaltlich-systematischen Gesichtspunkten zerstückelt und als Einzelexzerpte dann unter den jeweils passenden Rubriken oder Titeln eingeordnet wurden.

Jedoch schon in der "Dionysiana" werden die Papstbriefe offenbar nicht mehr so sehr als Briefe im eigentlichen Sinne betrachtet, sondern in erster Linie als „Steinbruch“ für einzelne päpstliche Rechtsaussagen, die in ihnen enthalten sind. Dies kann man daran erkennen, daß dort die Dekretalen der einzelnen Päpste zwar noch vollständig wiedergegeben werden, jedoch in Abschnitte unterteilt sind, die für jeden Papst separat durchnummeriert werden, nicht einzeln für jeden Brief ${ }^{45}$. Hier zeichnet sich offenbar schon der erste Schritt zur Vorbereitung auf eine thematisch geordnete Erfassung der päpstlichen Aussagen ab.

Die erste größere systematisch geordnete kanonistische Sammlung ist im Westen die «Breviatio canonum», die Fulgentius Ferrandus, Diakon der Kirche von Karthago, zwischen 523 und 546 nach den Anweisungen seines Bischofs zusammenstellte. Er lieferte - was ihm dann später von Cresconius vorgeworfen wurde und die unmittelbare Benutzbarkeit seiner Sammlung natürlich auch erheblich einschränkte - nicht die vollständigen Texte, sondern nur eine Liste von 232 Rubriken zusammen mit Angaben, welche Kanones gemeint seien. Trotzdem sollte er auch mit dieser extremen Vorgehensweise Nachfolger fin$\operatorname{den}^{46}$.

Dies bedeutet jedoch nicht, daß es nicht auch nach systematischen Kriterien angelegte Sammlungen gibt, die vollständige Papstbriefe überliefern. Als Beispiel wäre hier die im letzten Viertel des 9. Jahrhunderts in Norditalien, entweder in Vercelli oder Mailand, entstandene "Collectio Anselmo dedicata" zu nennen, die fast 300 Briefe und Exzerpte aus dem Briefkorpus Gregors I. re-

43 Hageneder (wie Anm. 18) S. 319.

44 Ebd. S. 327.

45 Fowler-Magerl (wie Anm. 31) S. 31.

46 Ebd. S. 27-29. 
zipierte $^{47}$. Aber auch hier wird das Eschatokoll und damit die Datumszeile häufig weggelassen, werden die Inskriptionen auch unvollständig oder gar nicht wiedergegeben.

Die Sammler, die vor der Mitte des 9. Jahrhunderts das pseudoisidorische Corpus zusammenstellten, haben sich wohl auch deshalb für die chronologische Ordnung entschieden, weil solche Sammlungen als vertrauenswürdiger galten. Neben den gefälschten Dekretalen findet man hier jedoch auch zahlreiche echte Konzilskanones und Dekretalen, die vor allem dem Zweck dienen sollten, die gefälschten Dekretalen in ein vertrauenerweckendes Umfeld zu betten ${ }^{48}$.

Besonders interessant für die Erfassung päpstlicher Schreiben sind wohl vor allem die Sammlungen, die nicht nur schon mehrfach tradiertes Material, sondern auch im größeren Umfang „neue“ Papstbriefe aufnahmen. Nach der spätantiken Phase des Dekretalenrechts hat es vor allem im 9. Jahrhundert eine Anreicherung des bisher überlieferten Dekretalenbestands gegeben und zwar zum einen durch Pseudoisidor und zum andern durch die «Collectio Anselmo dedicata", deren Autor, wie eben schon angesprochen - mehr als jeder andere Kanonist vor und nach ihm Gebrauch vom Briefregister Gregors I. machte ${ }^{49}$. Schreiben von Päpsten aus der Zeit von der Mitte des achten bis zur Mitte des neunten Jahrhunderts, also von Stephan II. (752-757) bis zu Gregor IV. (827844) sind dagegen - abgesehen von einigen Fälschungen und Fehlzuschreibungen, in den kanonistischen Sammlungen kaum vertreten ${ }^{50}$.

47 Landau: Rechtsfortbildung (wie Anm. 25) S. 88; Kéry (wie Anm. 32) S. 124-128; Fowler-Magerl (wie Anm. 31) S. 70-74. Vgl. jetzt auch Irene Scaravelli: La collezione canonica Anselmo dedicata: lo status quaestionis nella prospettiva di un'edizione critica, in: Le storie e la memoria. In onore di Arnold Esch, hg.v. Roberto Delle Donne/Andrea Zorzi, Florenz 2003, S. 33-52; vgl. dazu auch DA 62 (2005) S. 612.

48 Fowler-Magerl (wie Anm. 31) S. 50-55, v.a. S. 52. Vgl. jetzt auch Peter Landau: Gratians unmittelbare Quellen für seine Pseudoisidortexte, in: Fortschritt durch Fälschungen? Ursprung, Gestalt und Wirkungen der pseudoisidorischen Fälschungen. Beiträge zum gleichnamigen Symposium an der Universität Tübingen vom 27. und 28. Juli 2001, hg.v. Wilfried Hartmann/Gerhard Schmitz, Hannover 2002 (MGH Studien und Texte 31), S. 161-189.

49 Durch die Zusammenstellung dieser Schreiben in einem eigenen Abschnitt unter dem Titel „Gregorius" zwischen den mit Ius canonicum und Ius romanum überschriebenen Teilen, versuchte er offenbar auch diese neu aufgenommenen Gregorbriefe als Ius novum kenntlich zu machen. Dazu Peter Landau: Das Register Papst Gregors I. im Decretum Gratiani, in: Mittelalterliche Texte. Überlieferung - Befunde - Deutungen, Kolloquium der Zentraldirektion der MGH am 28./29. Juni 1996, hg.v. Rudolf Schieffer, Hannover 1996 (MGH Schr. 42) S. 125-140, hier S. 126; zur Rezeption der Gregorbriefe in kanonistischen Sammlungen vgl. auch Jörg Müller: Die Überlieferung der Briefe Papst Gregors I. im Rahmen der Collectio duodecim partium, in: Licet preter solitum. Ludwig Falkenstein zum 65. Geburtstag, hg. v. Lotte Kéry/Dietrich LohrmanN/Harald MüLler, Aachen 1998, S. 17-31.

50 Jasper (wie Anm. 17) S. 102. 
Der nächste große Schub einer Rezeption von Papstbriefen in Kanonessammlungen erfolgte dann erst wieder in der Zeit der Gregorianischen Reform, als viele neue Fragen zu Struktur und Verfassung der Kirche nach Antworten verlangten, die offenbar verstärkt auch in autoritativen Schreiben der Päpste gesucht wurden. In die zahlreichen Sammlungen der Reformzeit, die hauptsächlich in Italien, aber zum Teil auch nördlich der Alpen zusammengestellt wurden, wie z. B. die 74-Titel-Sammlung, die Sammlung des Kardinals Deusdedit oder Anselms von Lucca, aber auch die Werke Ivos von Chartres und Gratians Dekret, um nur einige der bekanntesten zu nennen, werden jedoch die päpstlichen Schreiben entsprechend der starken Ausrichtung auf bestimmte inhaltliche Leitthemen - wie etwa der unbedingten Unterwerfung unter das Urteil des Apostolischen Stuhls, der Beachtung der hierarchischen Ordnung oder auch der größeren Autorität der kirchlichen Gesetzgebung gegenüber dem weltlichen Recht - in Einzelexzerpte unterteilt und nach systematischen Gesichtspunkten eingeordnet. So enthält zum Beispiel das Dekret des Bischofs Ivo von Chartres 111 Exzerpte aus 44 Briefen Nikolaus' I. ${ }^{51}$ Deusdedit exzerpierte 15 Briefe Nikolaus' I. und teilte sie in 54 Teilstücke auf ${ }^{52}$.

Die Sammler der Reformzeit griffen also auch auf ältere Papstbriefe zurück, die bis dahin noch nicht in Sammlungen aufgenommen worden waren. Man kann sogar sagen, daß erst jetzt die meisten Anordnungen früherer Päpste, wie etwa Nikolaus' I., Leos IV., Pelagius' I., teilweise aber auch Gelasius' I. im kanonischen Recht wirksam wurden ${ }^{53}$. Eine gewisse Ausnahme stellen dabei die Briefe Nikolaus' I. dar, die zum Teil schon zu seinen Lebzeiten verbreitet wurden, jedoch nicht nach Abschriften aus seinen Registern, sondern nach denjenigen der Empfänger ${ }^{54}$. Sie sind also - was für diese Zeit sehr ungewöhnlich ist - bereits in zeitgenössischen Sammlungen zu finden, jedoch mit deutlichem geographischen Schwerpunkt im Frankenreich, unter anderem in Sammlungen Hinkmars von Reims oder auch in der möglicherweise aus Laon stammenden ${ }^{55}$ und im dritten Viertel des 9. Jahrhunderts entstandenen Handschrift Paris lat. 1557, die auch die wichtigste Quelle für Briefe Hadrians II., des Nachfolgers von Nikolaus I., darstellt ${ }^{56}$. Bei den Sammlern der gregorianischen Reformzeit sollten sich die Schreiben Nikolaus' I. dann v.a.

51 Ernst Perels: Die Briefe Papst Nikolaus' I., in: NA 37 (1912) S. 535-586; 39 (1914) S. 43-153, hier S. 105; vgl. Jasper (wie Anm. 17) S. 124.

52 Perels (wie Anm. 51) S. 75-86; vgl. Jasper (wie Anm. 17) S. 121.

53 Landau: Rechtsfortbildung (wie Anm. 25) S. 88.

54 JASPER (wie Anm. 17) S. 111.

55 John J. Contreni: Codices Pseudo-Isidoriani: The Provenance and Date of Paris, B. N. MS lat. 9629, in: Viator 13 (1982) S. 1-14.

56 Jasper (wie Anm. 17) S. 113. 
wegen seiner ausführlichen und klaren Äußerungen zur päpstlichen Autorität und den päpstlichen Vorrechten großer Beliebtheit erfreuen ${ }^{57}$.

Die Kenntnis zahlreicher Papstbriefe verdanken wir vor allem der längst noch nicht abschließend untersuchten, aber "für die Quellengeschichte des kanonischen Rechts kaum zu überschätzenden Collectio Britannica ${ }^{\text {“58 }}$. Sie eignet sich überdies besonders gut, um weitere Möglichkeiten aber auch Schwierigkeiten, die mit einer Auswertung von Kanonessammlungen verbunden sind, beispielhaft aufzuzeigen, denn die Einzigartigkeit der «Britannica» besteht unter anderem darin, daß sie echte päpstliche Dekretalen aus dem früheren Mittelalter von Gelasius I. bis Urban II. überliefert, von denen viele bis dahin noch nicht in den Sammlungen zu finden $\operatorname{sind}^{59}$ und von denen man auch sonst keine Kenntnis hatte. Dies zeigt das Beispiel Leos IV., von dem wir heute fast doppelt so viele Briefe und Brieffragmente kennen wie vor der Entdeckung und Auswertung der "Collectio Britannica» am Ende des 19. Jahrhunderts ${ }^{60}$, wobei jedoch - wie Klaus Herbers errechnet hat - der „Zuwachs an neuen Brieffragmenten Leos IV. durch die Entdeckung der Collectio Britannica nur einen kleinen Ausschnitt aus der gesamten Korrespondenz bieten dürfte ${ }^{\text {“61 }}$.

Die um 1090 (Somerville) oder möglicherweise auch erst nach 1094/1095 (Herbers) entstandene "Collectio Britannica» ${ }^{62}$, die heute nur noch in einer einzigen Londoner Handschrift vorliegt (BL Add. 8873) verweist zwar für ihre 233 Papstschreiben auf die Register Gelasius' I., Pelagius' I., Leos IV., Johannes' VIII., Stephans V., Alexanders II. und Urbans II. als Quelle, schöpfte aber offenkundig nicht unmittelbar aus den Registern, sondern aus Teilsammlungen,

57 Ebd. S. 111 mit Bezug auf Walter Ullmann: The Growth of Papal Government in the Middle Ages: A Study in the Ideological Relation of Clerical to Lay Power, London ${ }^{3} 1970$, S. 190. Im «Decretum Gratiani» rangieren die Texte, die auf diesen Papst zurückgehen, zahlenmäßig sogar unmittelbar hinter den Schreiben Gregors I. und noch vor denjenigen Gelasius' I. und Leos d. Gr.

58 Landau: Rechtsfortbildung (wie Anm. 25) S. 88. Vgl. auch Kéry (wie Anm. 32) S. 237 f.; Fowler-Magerl (wie Anm. 31) S. 184-187.

59 Peter Landau: Gefälschtes Recht in den Rechtssammlungen bis Gratian, in: Fälschungen im Mittelalter. Internationaler Kongreß der Monumenta Germaniae Historica, München, 16.-19. Sept. 1986, Teil II: Gefälschte Rechtstexte. Der bestrafte Fälscher, Hannover 1988 (MGH Schr. 33/2) S. 11-51, hier S. 40; Fowler-Magerl (wie Anm. 31) S. 184.

60 Klaus Herbers: Leo IV. und das Papsttum in der Mitte des 9. Jahrhunderts. Möglichkeiten und Grenzen päpstlicher Herrschaft in der späten Karolingerzeit, Stuttgart 1996 (Päpste und Papstttum 27), S. 49.

61 Ebd. S. 62.

62 Robert Somerville in Zusammenarbeit mit Stephan Kuttner: Pope Urban II, the Collectio Britannica and the Council of Melfi (1089), Oxford 1996, S. 23; dagegen Herbers (wie Anm. 60) S. 77 u. 89; vgl. dort auch S. 56. 
die vorher anhand der Register angefertigt worden waren ${ }^{63}$. Bemerkenswert ist dabei jedoch nicht nur, daß diese Registerauszüge anscheinend nur einige Jahre der jeweiligen Pontifikate umfaßten ${ }^{64}$, sondern daß neben den angeblich so authentischen päpstlichen Registern ${ }^{65}$ auch andere Quellen Material beigesteuert haben. So lieferte etwa die Sammlung des Kardinals Deusdedit die Vorlage für die meisten der vierzig Exzerpte aus 13 Briefen Nikolaus' I. ${ }^{66}$, die jedoch im Unterschied zu den Auszügen aus den Registern der übrigen Päpste erst im letzten Teil der Handschrift London BL Add. 8873, in den sogenannten „Varia 2", zu finden sind ${ }^{67}$. Manche Fragmente stammen aber auch aus viel älteren Sammlungen, wie z. B. dem "Liber auctoritatum ecclesiae Arelatensis» aus dem 6. Jahrhundert ${ }^{68}$, der eine Sammlung von Papstbriefen bis zu Pelagius I. (JK 938 von 557/58) enthält ${ }^{69}$.

Wichtig ist auch, daß fast alle Texte, die in die "Collectio Britannica» aufgenommen wurden, schon rein äußerlich als Fragmente erkennbar sind und auch die Angaben zu Aussteller und Empfänger häufig unvollständig und lükkenhaft sind. Die Anordnung der Sammlung wurde als „weder chronologisch noch systematisch" beschrieben ${ }^{70}$. Selbst die früher angenommene chronologische Abfolge innerhalb der Blöcke zu den einzelnen Päpsten trifft zumindest für Leo IV. nicht $\mathrm{zu}^{71}$ und auch für Alexander II. wurde sie in Frage gestellt ${ }^{72}$. Den Inhalt der "Collectio Britannica» bezeichnet Fowler-Magerl immer noch als „essentially Roman“, auch wenn die Sammlung - nach heutigen Erkenntnissen - offenbar in Nordfrankreich in ihre endgültige Form gebracht wurde, zumal,

63 Hageneder (wie Anm. 18) S. 325. Ausführliche Beschreibung der Handschrift bei Somerville: Urban II (wie Anm. 62) S. 8-14; zu Überlieferung und Struktur der Sammlung auch Herbers (wie Anm. 60) S. 49-51. Immer noch grundlegend für jede Beschäftigung mit der "Collectio Britannica»: Paul Ewald: Die Papstbriefe der Brittischen Sammlung, in: NA 5 (1880) S. 278-596.

64 So etwa die drei letzten Bücher Gelasius' I., die vier ersten Jahrgänge Johannes' VIII. (872-875), die vier ersten Jahre Stephans V. (885-888) und dann wieder die beiden ersten Jahre Urbans II. Hageneder schließt daraus, daß die Auswahl, welche die Sammler getroffen haben, eher zufällig war. HaGeneder (wie Anm. 18) S. 325 („Zwischensammlungen").

$65 \mathrm{Zu}$ der These von Walter Ullmann, daß ein verändertes Register Leos IV. zur Zeit des Investiturstreites für polemische Zwecke genutzt wurde, siehe unten Anm. 77.

66 Jasper (wie Anm. 17) S. 122; Fowler-Magerl (wie Anm. 31) S. 162.

67 Fowler-Magerl (wie Anm. 31) S. 184 f., dazu auch Jasper (wie Anm. 17) S. $122 \mathrm{f}$.

68 Fowler-Magerl (wie Anm. 31) S. $184 \mathrm{f}$.

69 Jasper (wie Anm. 17) S. 85-87, hier S. 87.

70 Somerville: Urban II (wie Anm. 62) S. 4.

71 Herbers (wie Anm. 60) S. 88.

72 Tilmann Sснмidt: Alexander II. (1061-1073) und die römische Reformgruppe seiner Zeit, Stuttgart 1977 (Päpste und Papsttum 11), S. 224-226. 
wie Martin Brett gezeigt hat, für einige Texte ein italienischer Ursprung höchst unwahrscheinlich ist ${ }^{73}$.

Trotz der wiederholten Quellenangabe ex registro in der einzigen Handschrift, London BL Add. 8873, wurden auch immer wieder Zweifel an der Authentizität einiger Stücke geäußert, die in dieser Sammlung überliefert sind ${ }^{74}$. So hat Stephan Kuttner gezeigt, daß der in der «Britannica» überlieferte Brief Urbans II. an Bischof Peter von Pistoia und den Abt von Vallombrosa (JL 5383) über die Weihe Daimberts von Pisa zum Diakon durch die Übernahme von Sätzen über die Interpretation von Kanones in Anlehnung an die berühmte Praefatio Ivos von Chartres zur «Panormia» erweitert wurde ${ }^{75}$. Zudem hat er auf die gegenüber Deusdedit und der "Collectio tripartita» unzuverlässigere Wiedergabe von Fragmenten aus einem Brief Nikolaus I. hingewiesen und gezeigt, daß in einen Brief Nikolaus' I. (JE 2796) an Kaiser Michael ein Text aus einem Brief Cyprians interpoliert wurde ${ }^{76}$.

Walter Ullmann zweifelte vor allem an der Echtheit einiger Briefe Leos IV., die in der "Collectio Britannica» überliefert werden ${ }^{77}$, und in seiner Darstellung des Pontifikats Gelasius' I. hat er sogar die 66 Gelasius-Texte der «Britannica»

73 Martin BREtT: Urban II and the collections attributed to Ivo of Chartres, in: Proceedings 8. IntKongrMK, San Diego, University of California at La Jolla, 21-27 August 1988, hg.v. Stanley Chodorow, Città del Vaticano 1992 (MIC C 9), S. 27-46, hier S. 35-37; vgl. Somerville: Urban II (wie Anm. 62) S. 14; Fowler-Magerl (wie Anm. 31) S. 184.

74 Vgl. dazu v.a. Herbers (wie Anm. 60) S. 53-58.

75 JL 5383; IP 3 S. 119 Nr. 2; Stephan KutTner: Urban II and the Doctrine of Interpretation: A Turning Point?, in: SG 15 (1972) S. 53-85, v. a. S. 58 f. (ND in: DERs.: The History of Ideas and Doctrines of Canon Law in the Middle Ages, London 1980 [Collected studies series 113], IV; ${ }^{2} 1991$ mit neuen ,Retractationes'). Vgl. Robert Somerville: The Letters of Pope Urban II in the Collectio Britannica, in: Proceedings 7. IntKongrMK, Cambridge, 23-27 July 1984, hg. v. Peter Linehan, Città del Vaticano 1988 (MIC C 8), S. 103-114, hier S. 106; Landau: Gefälschtes Recht (wie Anm. 59) S. 40-42; Herbers (wie Anm. 60) S. 55 mit Anm. 48.

76 Kuttner: Doctrine (wie Anm. 75) S. 81-83.

77 JE 2613, 2615 und 2646, CB Nr. 19, 21 u. 40. Vgl. dazu auch Herbers (wie Anm. 60) S. 54; Jasper (wie Anm. 17) S. 110 mit Anm. 93. Ullmann rückt diese Stücke in die Nähe des Investiturstreits. Sein Hauptargument war, daß die Briefe Nr. 19 u. 40 zum ersten $\mathrm{Mal}$ in dem Traktat «De penitentia regum» zitiert wurden, dessen Entstehung er mit dem Bußgang von Canossa 1077 in Verbindung bringt. Vgl. Walter Ullmann: Nos si aliquid competenter ... (Some observations on the Register Fragments of Leo IV in the Collectio Britannica), in: Ephemerides Iuris Canonici 9 (1953) S. 3-11 (ND in: DERs.: The Church and the Law in the Earlier Middle Ages, Selected Essays, London 1975, Nr. VII), hier S. 6, 10 f. Dies wurde jedoch von Claudia Märtl bestritten. Vgl. dazu Claudia MärTL: Ein angeblicher Text zum Bußgang von Canossa: „De paenitentia regum“, in: DA 38 (1982) S. 555-563. 
ganz bewußt nicht berücksichtigt ${ }^{78}$. Janet Nelson untersuchte den Brief Leos IV. über die Salbung König Alfreds d. Gr. und betrachtet ihn aufgrund von Inhalt und Sprache als eine Fälschung der 1060er oder 1070er Jahre, als Alexander II. und Gregor VII. versuchten, England mit Hilfe des Lehnrechts enger an den Hl. Stuhl zu binden ${ }^{79}$. Aufgrund dieses Befundes stellte Peter Landau sogar die Vermutung auf, daß gerade auch über die «Britannica» bzw. ihre unmittelbare Vorlage möglicherweise eine Reihe von Fälschungen ins kanonische Recht Eingang fand, die dann aufgrund der Traditionslinie "Britannica» - Ivo Gratian ins Ius commune der Kirche aufgenommen wurden ${ }^{80}$.

Auch Klaus Herbers knüpfte an seinen genauen Vergleich der von ihm in einer vatikanischen Handschrift neu aufgefundenen früheren Überlieferung des Briefes Leos IV. an die bretonischen Bischöfe (JE 2599) mit den in der "Collectio Britannica» und anderen kanonistischen Sammlungen überlieferten Version dieses Schreibens, der eine Reihe von Änderungen, v. a. von Weglassungen und Hinzufügungen, erbracht hat, die grundsätzliche Frage, wie authentisch

78 Vgl. Walter Ullmann: Gelasius I. (492-496). Das Papsttum an der Wende der Spätantike zum Mittelalter, Stuttgart 1981 (Päpste und Papsttum 18), S. 225-227, v.a. S. 227 Anm. 36. Eine eingehende Analyse der "Britannica» bezeichnete auch er als dringendes Forschungsdesiderat. Vgl. auch Landau: Gefälschtes Recht (wie Anm. 59) S. 41 .

79 CB 31, JE 2645; Janet L. NeLson: The problem of King Alfred's Royal Anointing, in: JEcH 18 (1967) S. 145-163 (ND in: DIEs.: Politics and ritual in early medieval Europe, London 1986 [History Series 42], S. 309-327, hier S. 311-327); JASper (wie Anm. 17) S. 110. Interpolationen wurden schließlich auch in dem Schreiben Leos IV. an die Bischöfe der Bretagne (JE 2599) festgestellt, vgl. LandAu: Gefälschtes Recht (wie Anm. 59) S. 41 und vor allem Herbers (wie Anm. 60) S. 67-78; vgl. dazu Ullmann: Observations (wie Anm. 77) S. 8; zu JE 2599 vgl. jetzt auch Rudolf Schieffer: Zum Umgang der Karolingerzeit mit Simonie, in: Scientia veritatis. Festschrift für Hubert Mordek zum 65. Geburtstag, hg.v. Oliver Münsch/Thomas Zотz, Ostfildern 2004, S. $117-126$, hier S. $117 \mathrm{f}$.

80 Landau: Gefälschtes Recht (wie Anm. 59) S. 41 f.; vgl. auch Herbers (wie Anm. 60) S. 66: „Die von der Forschung gegen die Echtheit mehrerer Leo-Fragmente erhobenen Einwände sind trotz der problematischen - jedoch aufgrund der Voraussetzungen nicht anders möglichen - Methode der inhaltlichen Untersuchung ernst zu nehmen". Zur Rezeption der «Britannica»-Dekretalen bei Ivo von Chartres und Gratian siehe Peter LANDAu: Wandel und Kontinuität im kanonischen Recht bei Gratian, in: Sozialer Wandel im Mittelalter. Wahrnehmungsformen, Erklärungsmuster, Regelungsmechanismen, hg.v. Jürgen Miethke/Klaus Schreiner, Sigmaringen 1994, S. 215-233, hier S. 221-229. Dort auch der für die Einschätzung der "Collectio Britannica» wichtige Hinweis, daß „solche Dekretalen für die Zeitgenossen des frühen 12. Jahrhunderts ius novum “ waren, ,auch wenn sie altehrwürdigen Päpsten zugeschrieben wurden“ (S. 222). Vgl. dort auch S. 230-233 die Zusammenstellung der Gratiantexte aus der «Collectio Britannica». 
eine Überlieferung in der «Collectio Britannica» und anderen kanonistischen Werken überhaupt sein könne ${ }^{81}$.

Allgemein wäre zu antworten, daß es trotz aller entsprechenden Erfahrungen im Einzelfall nicht von vornherein feststeht, daß die Überlieferung in der kanonistischen Sammlung die weniger zuverlässige ist. Grundsätzlich wäre auch noch einmal daran zu erinnern, daß die Unterschiede in der Überlieferung auch mit deren unterschiedlicher Zielsetzung zu tun haben. Wie oben schon im Zusammenhang mit der "Collectio Dionysiana» angesprochen, ging es den Sammlern nicht darum, ihren Benutzern im Stile moderner Textkritiker möglichst authentische päpstliche Schreiben im vollen Wortlaut zur Verfügung zu stellen, sondern bestimmte Rechtsvorstellungen und -vorschriften zu dokumentieren, bei denen es nur wenig darauf ankam, wann, für welchen Adressaten und in welchem Textzusammenhang sie formuliert wurden. Dabei ist sowohl mit Veränderungen der Texte als auch mit Verfälschungen im Dienste bestimmter Aussageabsichten zu rechnen, die möglicherweise mit dem ursprünglichen Inhalt des Schreibens nicht mehr viel zu tun haben, aber auch nicht von vornherein als Fälschungen zu bewerten $\operatorname{sind}^{82}$.

Die für unseren Gesamtzusammenhang ebenfalls lehrreiche Vermutung, daß die verschiedenen Teile der "Collectio Britannica" im Extremfall sogar eine jeweils eigene Vorgeschichte gehabt haben könnten ${ }^{83}$ und deshalb auch eine unterschiedliche historische und quellenkritische Bewertung verlangen, wird durch die Ergebnisse von Somerville bestätigt, der aufgrund seiner Untersuchungen zu den Briefen Urbans II. jedoch ein insgesamt positives Urteil über die Zuverlässigkeit zumindest dieses Teils der Sammlung gefällt hat. So erbrachte z. B. der Vergleich mit einem Brief Honorius' III. an den Erzbischof Rodrigo von Toledo vom 7. Januar 1218, in dem mehrere Briefe Urbans II. ausdrücklich als Kopien nach den Registern übermittelt werden, nur unbedeutende Varian$\operatorname{ten}^{84}$ und es gibt nach Somerville auch keine Anzeichen für weitere Textinterpolationen, wie sie Stephan Kuttner im Fall von JL 5383 festgestellt hat, noch irgendeinen Anlaß, die Authentizität eines der Urban II. zugeschriebenen Brieffragmente in Frage zu stellen ${ }^{85}$.

81 Herbers (wie Anm. 60) S. 72.

82 Ebd. S. 78: „Der Vergleich des Briefes JE 2599 mit der frühen Überlieferung zeigte ferner, daß Auslassungen vor allem das in Briefen übliche Beiwerk betrafen, zuweilen allerdings auch wichtige Sätze oder Satzteile mit der Tendenz zur ,Verfälschung'“.

83 Ebd. S. 63.

84 Vgl. dagegen das Urteil ebd. S. 64, über die Qualität der Hs. London, BL Add. 8873: "Offensichtlich wurde die Handschrift der Britischen Sammlung nicht mit allzu großer Sorgfalt angelegt“, bzw. S. 78: „relativ flüchtige Abfassungsweise“. Vgl. dazu auch BRETT: Collections (wie Anm. 73) S. $33 \mathrm{f}$.

85 Somerville: Letters (wie Anm. 75) S. 111; Herbers (wie Anm. 60) S. 56 f. 
Als besonders schwierig stellt sich natürlich die Einordnung der Papstbriefe dar, die allem Anschein nach allein in der "Collectio Britannica» überliefert sind - im Fall Urbans II. sind das 24 Texte $^{86}$. Die Schwierigkeiten beginnen schon bei der Bestimmung der Empfänger, denn der Abschnitt in der "Collectio Britannica», der Urban II. gewidmet ist, gehört zu dem Teil der Handschrift, dessen Rubriken fehlen ${ }^{87}$. Die einzigen Angaben zu den Adressaten finden sich in stark abgekürzten Randbemerkungen, die offenbar erst in einem späteren Arbeitsgang von einem Rubrikator in den Text eingefügt werden sollten; mehrere von ihnen wurden zum Teil herausgeschnitten, als man die Seiten neu ordnete $^{88}$.

Als ein Beispiel für die daraus resultierenden Schwierigkeiten führt Somerville das Schreiben JL 5380 an, das Paul Ewald auf der Grundlage einer fragmentarischen Inskription Petro ... si episcopo in Analogie zu dem eben schon genannten Schreiben an Bischof Petrus von Pistoia (1085/86-1101 - JL 5383), ebenfalls diesem als Empfänger zuordnete ${ }^{89}$. Im Text von JL 5380 heißt es, der Papst werde pro tempore die Wahl und Weihe des angesprochenen Bischofs tolerieren, obwohl er gehört habe, dass seine Erhebung auf unkanonische Weise vonstatten gegangen $\mathrm{sei}^{90}$. Allein auf diese unsichere, durch keine anderen Argumente abgesicherte Zuschreibung wurde bisher die Behauptung gestützt ${ }^{91}$, daß bei der Erhebung des Bischofs Petrus von Pistoia nicht alles mit Rechten Dingen zugegangen sei - eine, wie Somerville zu Recht moniert, ziemlich gewagte Vermutung, denn es sind auch andere Adressaten denkbar - wie z.B. Petrus von Terrracina, der ebenfalls in einem weiteren Fragment eines Schreibens Urbans II. in der "Collectio Britannica» mit der Inskription Petro Terracinensi auftaucht (JL 5353) ${ }^{92}$. Dieser kurze Text beginnt zudem mit der beziehungsreichen Feststellung: Multa videntur mala, que mala non sunt, quia mala intencione non fiunt, die Somerville treffend als "language of dispensation“ charakterisiert $^{93}$. Als dritte Möglichkeit hat Somerville später auch noch Bischof Petron von León vorgeschlagen, der ebenfalls in einem weiteren Brief der "Collectio Britannica» (CB 37) als Adressat angesprochen und dort auch passend als Sünder bezeichnet wird. Hier weicht jedoch die Schreibweise Petron von allen anderen Randglossen für Petro ab, die jeweils abgekürzt sind ${ }^{94}$. Angesichts

86 Somerville: Letters (wie Anm. 75) S. 108.

87 Ebd. S. 107; DERs.: Urban II (wie Anm. 62) S. 21.

88 Somerville: Urban II (wie Anm. 62) S. 37.

89 JL 5380; IP 3 S. 119 Nr. 1; Somerville: Letters (wie Anm. 75) S. 109; vgl. auch Ewald (wie Anm. 63) S. 359 Nr. 25 mit Anm. 4.

90 Somerville: Urban II (wie Anm. 62) S. $94 \mathrm{f}$.

91 Vgl. z. B. Kuttner: Doctrine (wie Anm. 75) S. 57.

92 Somerville: Letters (wie Anm. 75) S. 109; Ders.: Urban II. (wie Anm. 62) S. 48-50.

93 Ebd. S. 49.

94 Ebd. S. 95 (zu CB 25). 
solcher wenig eindeutigen Konjekturen, die das Problem der Adressatenbestimmung bei den in Kanonessammlungen überlieferten Papstbriefen noch einmal plastisch vor Augen führen, ist festzuhalten, daß sich die Frage nach dem Adressaten von JL 5380 wohl kaum beantworten läßt, solange keine weitere Überlieferung mit vollständigerer Inskription auftaucht - der Inhalt des Schreibens liefert jedenfalls keinerlei Anhaltspunkte.

Wichtige Quellen für päpstliche Briefe in der kanonistischen Literatur des endenden 11. und beginnenden 12. Jahrhunderts stellen neben der «Britannica» auch chronologisch nach Pontifikaten angeordnete Sammlungen von Papstbriefen bzw. Auszügen aus Papstbriefen dar, wie sie in der wohl in Chartres entstandenen "Collectio Tripartita $A »{ }^{95}$ oder der bisher noch nicht genauer untersuchten italienischen Sammlung in der Handschrift BAV, Vat. lat. 3829 vorliegen ${ }^{96}$. Bekannt ist jedoch, daß diese letztgenannte Sammlung einen besseren Text des Briefes Nr. 144 der "Collectio Britannica» (Varia 2.131) aufweist, der auch noch in weiteren Sammlungen zu finden ist. Jedoch allein aus der Version im Vat. lat. 3829 erfahren wir, daß die in diesem Brief enthaltenen Instruktionen Nikolaus' I. an Bischof Braidingus von Mâcon (853-862) gerichtet waren ${ }^{97}$.

Die beiden zuletzt genannten Sammlungen werden ebenso wie die "Collectio Britannica» zur Gruppe der sogenannten „Zwischensammlungen“ gezählt, die man auch als bloße Materialsammlungen bezeichnen könnte, da sie noch nicht über eine deutlich erkennbare inhaltliche Systematik verfügen. Sie stehen für eine Reihe nicht erhaltener Sammlungen, auf deren Spuren man bei einer genaueren Untersuchung der Abhängigkeitsverhältnisse zwischen den heute noch vorliegenden Sammlungen immer wieder trifft und die man sich gemeinhin als längere Exzerptreihen vorstell $t^{98}$. Nach Ansicht von Forschern wie Sickel, Perels, Fournier und Fuhrmann sind sie in den letzten Jahren Gregors VII. entstanden ${ }^{99}$. Auf solche nicht erhaltenen Zwischensammlungen gehen zum Teil bedeutsame inhaltliche Varianten gegenüber den Registerversionen zurück, wie etwa in dem berühmten Brief Gregors VII. an Hermann von Metz, in dem der Papst die Exkommunikation und Absetzung Heinrichs IV. zu

95 Jasper (wie Anm. 17) S. 60 f. Zur «Collectio Tripartita» vgl. Fowler-Magerl (wie Anm. 31) S. 187-190; Kéry (wie Anm. 32) S. 244-250.

96 Vgl. dazu ebenfalls den sehr instruktiven Überblick bei Fowler-Magerl (wie Anm. 31) S. $216-218$.

97 Jasper (wie Anm. 17) S. 123.

98 Zur Problematik der Zwischensammlungen für den Historiker vgl. auch Herbers (wie Anm. 60) S. 63.

99 Vgl. Jasper (wie Anm. 17) S. $121 \mathrm{f}$.: „Scholars believe that these putative collections would have been written in the last years of Pope Gregory VII's pontificate. Since the materials of these collections were generally merged into other collections, they have disappeared“. Vgl. dort auch Anm. 151 u. 152 sowie Herbers (wie Anm. 60) S. 52. 
rechtfertigen versuchte ${ }^{100}$. In der "Collectio intermedia», die Anselm von Lucca und Deusdedit hier als gemeinsame Vorlage diente, wurde das Wort deposuisse gegenüber der Registerversion offenbar ausgelassen, denn die inhaltlich bedeutsame Variante findet sich sowohl bei Anselm als auch bei Deusdedit ${ }^{101}$.

Aber auch „kleinere" und bisher noch weniger bekannte Sammlungen können wichtige Einzelheiten zur besseren Kenntnis der Papsturkunden beitragen. Besonders vielversprechend ist zum Beispiel die erst in den letzten Jahren zu größerer Beachtung gelangte Sammlung in der Handschrift Paris, Bibliothèque de l'Arsenal 713, die inzwischen nicht nur als wichtige Quelle für das Dekret Ivos von Chartres erkannt wurde ${ }^{102}$, sondern auch deshalb zu neuer Bedeutung gelangte, weil ihre Existenz beweist, daß es eine noch ausführlichere Überlieferung der "Collectio Britannica» gegeben haben muß, als sie uns in der einzigen bisher bekannten Handschrift vorliegt ${ }^{103}$.

Der Codex Paris, Biblothèque de l'Arsenal 713 stammt aus der Abtei SaintVictor, die zahlreiche Handschriften aus Chartres besaß, und besteht aus zwei voneinander unabhängigen Teilen ${ }^{104}$. Der erste Teil (fol. $1-116 v$ ) enthält eine Abschrift der «Panormia», der zweite (fol. 117-192v, von Somerville als 713B bezeichnet), dessen Herkunft unbekannt ist, die uns hier interessierende Sammlung. Einige Bruchstücke von Briefen der Päpste Johannes VIII., Alexander II. und Urban II. wurden nach dieser Handschrift schon 1618 in der

100 JL 5201; Das Register Gregors VII., hg.v. Erich Caspar, Berlin 1923 (MGH Epp. sel. 2/ 2), VIII/21 S. 544-563, hier S. 551, Z. 3-7.

101 Anselmi episcopi Lucensis Collectio canonum una cum collectione minore, ed. Friedrich Thaner, Innsbruck 1906, I 80 S. 53-55; Die Kanonessammlung des Kardinals Deusdedit, ed. Victor Wolf von Glanvell, Paderborn 1905, IV 184 S. 489-491; Hageneder (wie Anm. 18) S. 324 f., vermutet sogar, daß Deusdedit selbst eine solche Zwischensammlung kurz vor der Abfassung seiner eigentlichen Kanonessammlung anlegte; jedenfalls ist auch in seiner Sammlung nicht klar, was direkt aus den päpstlichen Archiven stammt und was aus einer Quelle, die gleichzeitig auch von Anselm von Lucca benutzt wurde, ebd. S. 324 Anm. 24.

102 Peter Landau: Das Dekret des Ivo von Chartres. Die handschriftliche Überlieferung im Vergleich zum Text in den Editionen des 16. und 17. Jahrhunderts, in: ZRGKanAbt 70 (1985) S. 1-44, hier S. 33 (ND in: Ders.: Kanones und Dekretalen, Goldbach 1997, S. $117^{*}-160^{*}$ und 473*-474); Somerville: Urban II (wie Anm. 62) S. 16, und vor allem Martin BRETt: The Sources and Influence of Paris, Bibliothèque de l'Arsenal MS 713, in: Proceedings 9. IntKongrMK, Munich, 13-18 July 1992, hg.v. Peter Landau/ Jörg Müller, Città del Vaticano 1997 (MIC C 10), S. 149-167, hier S. 150-156; Fowler-Magerl (wie Anm. 31) S. $192 \mathrm{f}$.

103 Robert Somerville: Papal Excerpts in Arsenal MS 713B: Alexander II and Urban II, in: Proceedings 9. IntKongrMK, Munich, 13-18 July 1992, hg.v. Peter Landau/Jörg Müller, Città del Vaticano 1997 (MIC C 10), S. 169-184, hier S. 173; BRETT: Collections (wie Anm. 73) S. 34; Somerville: Urban II (wie Anm. 62) S. 15-19, 27.

104 Zur Handschrift Brett: Sources (wie Anm. 102) S. 149 f.; Somerville: Papal Excerpts (wie Anm. 103) S. 169-173. 
zweiten Edition der Konziliensammlung des Severinus Binius publiziert, der dieses Material von dem Victoriner Jean Picard erhielt. Aus den «Concilia generalia» des Binius fanden diese Texte auf dem bekannten Weg über die nachfolgenden Konzilssammlungen Eingang in die Editionen von Mansi und Migne und wurden schließlich auch in der zweiten Auflage der Regesta pontificum Romanorum verzeichnet ${ }^{105}$.

Picard hatte Binius jedoch nur mit einer winzigen Probe von päpstlichen Texten versorgt, die in der Sammlung der Arsenal-Handschrift zu finden waren ${ }^{106}$; sie enthält allein 32 Fragmente, die Alexander II. zugeschrieben werden können und alle auch durch die "Collectio Britannica» überliefert werden, sowie 22 Stücke, die auf Urban II. zurückgehen, von denen jedoch nur 16 auch in der "Collectio Britannica» enthalten sind ${ }^{107}$.

Obwohl also schon einige Stücke aus dieser Handschrift seit langem durch die Drucke von Mansi und Migne bekannt und auch in den Regesta pontificum Romanorum zu finden sind, zeigt erst eine genauere Analyse dieser Handschrift in ihrem Gesamtzusammenhang, wie wertvoll ihre Überlieferung von Papstbriefen für die Rekonstruktion der jeweils authentischen Texte ist. Aufgrund ihres äußeren Erscheinungsbildes - es handelt sich um einen weder in Bücher noch in Titel eingeteilten und kontinuierlich in langen Zeilen ohne Kolumnen über die Seiten geschriebenen Text, der ohne Rubriken auskommt und nur in wenige Absätze unterteilt ist - könnte man die Sammlung in der Handschrift Arsenal 713 ebenfalls für eine bloße Materialsammlung halten ${ }^{108}$. Wie Martin Brett jedoch festgestellt hat, wurden ihre Texte, im Unterschied zur «Britannica» in thematisch sinnvollen Abschnitten angeordnet. Das heißt, die Sammlung in der Arsenal-Handschrift repräsentiert eine etwas weiter fortgeschrittene Entwicklungsstufe auf dem Weg zu einer systematischen Sammlung ${ }^{109}$. Zudem machte sie offenbar von einer Vorlage Gebrauch, die zwar der «Collectio Britannica» ähnlich war, aber vollständigere Inskriptionen und bessere Texte bot ${ }^{110}$.

Einige von Somerville angeführte Beispiele beleuchten auch die Möglichkeiten, die die Sammlung in der Handschrift Paris, Bibliothèque de l'Arsenal 713 für das Studium der Papstbriefe bietet, und zeigen, welche Art von neuen Informationen sie über die päpstliche Korrespondenz liefern kann ${ }^{111}$.

105 Ebd. S. 169.

106 Ebd. S. 171.

107 Ebd. S. $171 \mathrm{f}$.

108 Brett: Sources (wie Anm. 102) S. 149 f.; Somerville: Papal Excerpts (wie Anm. 103) S. 171.

109 BRETT: Sources (wie Anm. 102) S. 167: „In the Arsenal collection the re-organisation of material by topic is more or less incomplete".

110 Somerville: Papal Excerpts (wie Anm. 103) S. 173.

111 Ebd. S. 177. 
- Der in der "Collectio Britannica» nur mit Girardo episcopo inskribierte Brief Alexanders II. (JL 4551), dessen Adressat Paul Ewald mit dem Bischof Gerald von St-Paul-Trois-Châteaux und Orange identifizierte, ist aufgrund der Inskription in der Arsenal-Handschrift nun als Schreiben an Bischof Gerald von Sisteron einzuordnen ${ }^{112}$.

- Die ausgedehnte, von Passau bis Pavia reichende Suche nach dem Adressaten des mit Odolrico episcopo inskribierten Briefes JL 4616, der in der Italia pontificia nicht verzeichnet ist ${ }^{113}$, kann aufgegeben werden: Gemäß der vollständigeren Inskription in der Handschrift Arsenal 713 (Alexander II Odolrico Forocornellii episcopo) handelt es sich um den Bischof Odelrich von Imola $^{114}$.

- Auch für den wichtigen Brief JL 5404 (IP -), durch den Urban II. einen Bischof darüber informiert, daß es zweckmäßig sei, ihm, d. h. dem Bischof, die Entscheidung zu überlassen, ob ein gefallener Kleriker wieder in sein Amt eingesetzt werde, bietet Arsenal 713 die gegenüber der "Collectio Britannica» ausführlichere Inskription Mantuano episcopo. Der gregorianische Bischof Ubald von Mantua, der hier allem Anschein nach gemeint ist, wurde 1091 von Heinrich IV. abgesetzt; der Brief kann also zusätzlich auch noch genauer datiert werden und zwar in die Zeit vor April 1091, wenn man mit Somerville voraussetzt, daß Urban II. einen von Heinrich IV. abgesetzten Bischof nicht mehr als solchen angesprochen hätte ${ }^{115}$.

Die aufgrund dieses Befundes wohl nicht ganz unberechtigte Erwartung, daß in der Sammlung der Arsenal-Handschrift auch bisher noch nicht bekannte Papstbriefe oder zumindest Textpassagen aus Papstbriefen enthalten sein könnten, wurde jedoch bisher enttäuscht - mit einer Ausnahme: JL 2965, ein Schreiben Johannes' VIII., enthält in dieser Handschrift eine Zeile mehr als in den anderen von ihm bekannten Versionen: simulque omnibus rebus maritalibus manere privatam ${ }^{116}$. Somerville weist jedoch ausdrücklich darauf hin, daß ähnliche Funde bei den noch nicht näher untersuchten Texten von Päpsten vor dem 11. Jahrhundert in der Handschrift Arsenal 713B zu erwarten seien ${ }^{117}$.

Ein letztes Beispiel soll schließlich auch noch davor warnen, zu schnell und unbesehen die Zuschreibungen in den kanonistischen Sammlungen zu übernehmen. Es geht um den bekannten, bisher Gregor VII. zugeschriebenen Brief an Bischof Guitmund von Aversa (JL 5277), in dem der Papst den Bischof an die Worte Christi im Johannesevangelium $(14,6)$ erinnerte: Ego sum veritas et

112 Ebd. S. 173 f.

113 Ebd. S. 181 Nr. 6: Italia pontificia vacat.

114 Ebd. S. 174.

115 Ebd. S. $174 \mathrm{f}$.

116 JL 2965; IP 4 S. 221 Nr. 2; vgl. Somerville: Papal Excerpts (wie Anm. 103) S. 175.

117 Ebd. S. 175 Anm. 21. 
vita und ihn gleichzeitig daran erinnerte, daß Christus keinesfalls gesagt habe Ego sum consuetudo ${ }^{118}$. Das entsprechende Exzerpt ist weder in der "Collectio Britannica» noch in der «Tripartita A» zu finden. Allem Anschein nach taucht es zum ersten Mal im Dekret Ivos von Chartres auf ${ }^{119}$. Von dort fand es seinen Weg in die "Panormia» und anschließend in die «Collectio decem partium» ${ }^{120}$; über die Neuordnung von Ivos Dekrets im dritten Teil der «Tripartita» wurde es schließlich in das «Decretum Gratiani» aufgenommen (Dist. 8 c. 5$)^{121}$. In allen Handschriften, die Somerville dazu im Einzelnen überprüft hat ${ }^{122}$, wird dieser fragmentarische Text Gregor VII. zugeschrieben, allein in der Handschrift Paris Arsenal 713B wird Urban II. als Absender genannt: U.ii. Wimundo Aversano episcopo, obwohl diese letztgenannte Lesart historisch gesehen wesentlich glaubwürdiger ist, denn Guitmund wurde erst unter Urban II. zum Bischof von Aversa erhoben ${ }^{123}$; zudem konnte das inzwischen berühmte Zitat an keiner anderen Stelle in der Korrespondenz Gregors VII. nachgewiesen werden, wohl aber bei Urban II. in einem Brief an den Grafen Robert I. von Flandern (JL 5471).

Für die vorgratianischen Sammlungen kann also festgehalten werden, daß sie wichtige Beiträge zur Erschließung, Erfassung und historischen Einordnung der päpstlichen Schreiben liefern, auch wenn man die damit verbundenen methodischen Schwierigkeiten nicht unterschätzen sollte, die vor allem aus ihrer speziellen Zielsetzung resultieren. Wie allein schon an den wenigen hier vorgestellten Beispielen gezeigt werden konnte, die bei einer Berücksichtigung weiterer Sammlungen noch deutlich vermehrt werden könnten, enthalten sie nicht nur das ein oder andere Schreiben, das in keiner anderen Überlieferung faßbar ist, oder auch zusätzliche Textpassagen, sondern auch - wenn auch eher selten - zusätzliche Informationen, die für die Identifizierung von Absender und Empfänger der Schreiben und manchmal sogar für eine genauere Datierung genutzt werden können.

Überdies dürfte deutlich geworden sein, daß die Möglichkeiten einer adäquaten Erfassung von Papstbriefen aus den Kanonessammlungen auch in ganz erheblichem Maße von den Fortschritten der kanonistischen Forschung abhängen, die nicht nur für die Erschließung neuen Materials, sondern auch für eine bessere Kenntnis oder gar Neubewertung von Papstbriefen zu nutzen sind.

118 JL 5277; IP -.

119 Decretum Ivonis, IV, c. 213, ed. Migne PL 161 Sp. 311; vgl. Somerville: Papal Excerpts (wie Anm. 103) S. 177.

$120 \mathrm{Zu}$ dieser Sammlung vgl. Kéry (wie Anm. 32) S. 263 f.; Fowler-Magerl (wie Anm. 31) S. 209-214 mit allen weiteren Angaben.

121 Emil Friedberg: Corpus iuris canonici, Bd. 1, Leipzig 1879 (ND Graz 1995), Sp. 14.

122 Somerville: Papal Excerpts (wie Anm. 103) S. 178 Anm. 33 u. 35.

123 Somerville: Papal Excerpts (wie Anm. 103) S. 178 f. 


\section{Riassunto}

Quali fonti che tramandano dei documenti pontifici in modo indiretto, le raccolte canonistische, compilate prima di Graziano, pongono problemi in parte considerevoli per la ricostruzione e classificazione dei testi - analogamente alle successive raccolte delle decretali. Ciò è dovuto soprattutto al fatto che servono a mettere insieme e ordinare il materiale per scopi legati al diritto ecclesiale. I destinatari e le datazioni sono secondari, sicché spesso non si menzionano affatto, o solo in modo incompleto, mentre nelle raccolte sistematiche i testi vengono tagliati e inseriti in diversi settori tematici. Queste riserve possono sì suscitare dei dubbi sull'autenticità dei testi che non sempre provengono direttamente dai registri papali, ma in parte sono stati tramandati indirettamente, e in parte addirittura in più versioni; ciononostante le raccolte canonistiche sono indispensabili per la rilevazione dei documenti quanto più completa possibile, non solo perché esse possono racchiudere brani di testo non rintracciabili da nessun'altra parte, ma anche perché a volte contengono ulteriori informazioni utili sia per l'identificazione di mittenti o destinatari sconosciuti che per una datazione più precisa. Le possibilità di rilevare in modo adeguato le lettere papali dalle raccolte canoniche dipendono pertanto in misura considerevole dai progressi fatti dalla ricerca canonistica. 
Bereitgestellt von | De Gruyter / TCS

Angemeldet | 217.89.40.26

Heruntergeladen am | 21.12.12 10:49 